\title{
A Utility-Theoretic Method of Computing Value of Disease Effects for Economic Evaluation of Health Program
}

\author{
Sushil Ranjan Howlader* \\ Professor of Health Economics, University of Dhaka, Bangladesh \\ *Corresponding Author: Sushil Ranjan Howlader, Professor of Health Economics, University of Dhaka, Bangladesh.
}

Received: August 12, 2019; Published: September 13, 2019

\begin{abstract}
The cost-utility techniques of economic evaluation, including the disability-adjusted life years (DALYs), are widely used at present for economic evaluation of health programs throughout the world. Although the measures have several advantages, they have some limitations too. They capture only the effect on health, although a disease can have effects on household income and engender medical and non-medical expenditures as well. It expresses the value of disease effect in terms of years and hence is not suitable for conducting economic evaluation because the other variable involved in evaluation is program cost that is always estimated in money. It also does not consider the opinions of the sick individuals about the effects of disease, which is highly necessary for computing the subjective variable like utility. More importantly, the amount of GDP loss obtained by using DALY measure is greatly underestimated if the disease or condition causes less mortality but high morbidity (such as HIV/AIDS). In that case the program that is undertaken to eliminate a difficult disease or reduce its burden can rarely be justified, because the cost may often exceed the estimated value of DALYs to be averted by the program. As such, many essential programs will be rejected if the DALY criterion of evaluation is used. This paper devises an alternative method of computing the three types of effects --- effect on health, on income and expenditure --- based on the utilitarian approach and expressing the value in terms of utility and money. It also proposes a formula for conducting economic evaluation of a health program. The formula was applied to the selected patients of costly diseases of a hospital in Bangladesh and it was found that even a very expensive program is fully justified for combating those diseases. The method was also used to assess the viability of undertaking an HIV/AIDS elimination program. The total value of the disease effects (VODE) as well as DALYs was calculated for selected patients under the program. A comparison reveals that the program is justified if it is judged based on VODE and not if judged based on the DALY measure.
\end{abstract}

Keywords: Disease; Economic Evaluation; Health Program

\section{Introduction}

A disease can create two broad types of effects on the diseaseafflicted individual and his/her household: effect on the health status of the individual, which includes morbidity and mortality, and on the household economy, which includes income loss and expenditures for health care. Estimation of the effect of disease on health of the people is needed to assess the health status of the population at a point in time as well as to judge the relative burden of diseases, so as to enable the policy makers to prioritize the diseases for identifying the interventions, given the resource constraints, to eradicate the diseases. On the other hand, the value of the economic effects--- income loss and expenditures-shows the economic benefits of health care and health program. The estimated amount of economic effects explicates the possible effect of health care on individual productivity of the sick persons and on GDP and poverty reduction. The two types of effects constitute the total effect of a disease and the value of total effects of diseases can more accurately and comprehensively embody the damages caused by them. More importantly, the value of the total effect is crucially needed, along with the cost of interventions for eradication of diseases, for properly conducting an economic evaluation, especially the costbenefit analysis, of the interventions. Hence, it is indispensable to derive an appropriate measure of the total effects of any disease.

Some measures of the disease effects already exist. Among them, the disability- adjusted life years (DALYs) and the qualityadjusted life years (QALYs) are the most widely used measures. Each measure has many advantages. The QALY measure is simple, and can be used for comparing the interventions yielding different outcomes. Besides, it is based on the weights of quality of health ascribed by the sick individual himself and as such it is closer to the value of utility and the method can be considered as a technique of cost-utility analysis. The DALY measure is more suitable to be used for assessing the status of global and regional health, as against the QALY which is applicable for assessing the effect of a health care especially that provided at a hospital. However, the two measures have some shortcomings as well. Each of the two measures can estimate only one type of effect of a disease--- that on health, and not 
the other type of effect-that on the economy. Hence, they capture only one part of the disease burden, although they are widely treated as the measures of entire disease burden. Second, each measure obtains the value of disease effect on health in terms of years, either lost or gained. On the contrary, the amount of income loss and expenditures incurred are found in the units of money; so is the cost of an intervention or program. The sum-total of the two types of effects cannot be obtained, given the different units of value. As a result, those measures cannot obtain the total amount of effect of disease or the full effect of health care on the sick persons. Hence, full and appropriate economic evaluation of health care programs cannot be conducted using those measures.

The main objective of the paper is to derive a measure that can capture all types of effects of a disease and that can show directly the money value of the effects as well as the loss of utility caused by the disease. Section 2 discusses the analytical framework of all effects of a disease: effect on health, income loss, and expenditure incurred. The section is derived based on the utilitarian approach of the classical economics. Section 3 operationalizes the framework and simplifies the measure so as to make it more applicable. Section 4 shows how the measure can be used for economic evaluation. Section 5 presents the results of case studies and economic evaluation of an ongoing health program Section 6 summarizes and concludes.

\section{An analytical framework}

As mentioned at the outset, a disease creates several types of effects on the sick individual as well as to his/her household and the society at large. The effects are: effect on health, productivity loss, and medical and non-medical expenditures for healthcare. The last two types of effects are economic and are easily observable and measurable in terms of money. The first type of effects refers to the physical and mental pain, suffering, and disability; it is fully non-economic in nature and it is difficult to obtain an estimate of its money value. On the other hand, it is also difficult to separate the private component from the social component of each type of disease effects. The private effect includes the effects on the individual and his/her household. Besides this, disease inflicted on an individual also affects the community/society of the sick person.

Given the heterogeneous nature of the disease effects, it is only the utility (or disutility) which can combine all effects into one magnitude and properly reflect the total effect of a disease. It is quite reasonable and realistic to assume that utility of an individual/household and society depends on health and economic productivity of their members. A disease inflicted on an individual reduces utility by way of reducing health status (h) and productivity/ income (y). The utility function of a household can be written as:

(1) $\mathrm{u}=u(h, y) ; \frac{\partial u}{\partial h}>0, \frac{\partial u}{\partial y}>0$ y includes both labor income and asset income. Medical and non-medical expenditures (E) can be considered as negative income and thus merged with y. A disease reduces productivity or labor income and increases expenditure which may be financed out of both labor income and asset income. Thus, disease affects health status and all components of income.

The two components of utility, one depending on $h$ and other on y (and E) are separable, so that Eq. (I) can be written as:

$u=u_{1}(h)+u_{2}(y)$

where $u_{1}(h)$ is the effect on health and $u_{2}(y)$ is the effect on income/expenditure (or economic effects). The effects can be separately discussed before they are combined to assess the total effect.

\section{Measurement of effect of a disease on health: utilitarian approach}

The utilitarian school of the classical economists admonished, in contradistinction with Ricardo's Labor Theory of value, that the value of a commodity is equal to its total utility. The theory of this school implies that equilibrium amount of commodity is determined in the market at the point where total utility is equal to total expenditure on the commodity. According to Marshall, the founder of the neoclassical school, the value of a commodity as well as equilibrium demand is determined at the point where marginal utility is equal to marginal spending (price), and equilibrium output is determined at the point of equality of demand and supply. The difference between the two views can be shown in the following figure. The equilibrium is at a according to the utilitarian view and at $b$ according to the neoclassical theory.

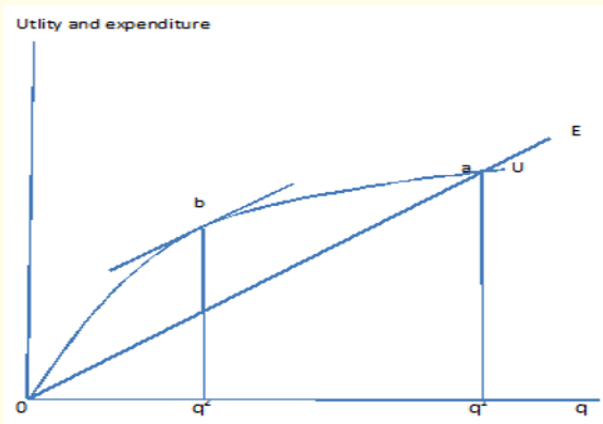

Figure 1: Consumer's equilibrium in utilitarian and neoclassical views.

The equilibrium amount is much lower $\left(\mathrm{q}_{2}\right)$ in the neoclassical theory than in the utilitarian view $\left(\mathrm{q}_{1}\right)$.

The neoclassical argument is consistent with the behavior of a consumer in the real market situations inasmuch as it enables him to maximize consumer's surplus. Marshall propounded the law of 
diminishing marginal utility and derived the downward-sloping demand curve from the total utility curve, and the marginal utility curve formed the basis of the downward sloping demand function obtained by him.

It is well known that the situation in the health sector is different from the private sectors. For most goods and services in the health sector, market does not exist and also should not exist, given the high externality and public good character of these goods, if social welfare is to be maximized through optimum use of resources. When a household receives healthcare for its sick member, its primary objective is to get as much healthcare as is medically required and not to maximize consumer's surplus. It is very likely that the household is willing, either on its own or with the support of the society/government, to pay the full amount of money that is needed to use the required amount of healthcare. As such, for the required amount of healthcare, its total utility is equal to the total expenditure incurred and total expenditure can be considered as the measure of total utility. The equilibrium point is a.

In order to elaborate the process of equilibrium determination for healthcare in the non-market situation, we assume that utility of a household is the function of the life years of its members. The life years $(t)$ of a household member yield utility of health and generate income to the household which also yields utility. Total utility of the household thus directly depends on income and health status of its members and indirectly on life years of them. In other words, a life year t gives income and health status, and income and health status yield utility to the household. Let us consider the utility of the household from the life years of one of its members. The member has the expected life span of $\mathrm{T}$ years, so that $\mathrm{t}=1,2, \ldots, \mathrm{T}$. Total utility ( $u$ ) of the household from any of its members is the function of income and health status of the member and both income and health status are the functions of life years, so that $u=u$ $(\mathrm{y}, \mathrm{h})$ and $\mathrm{y}=\mathrm{y}(\mathrm{t})$ and $\mathrm{h}=\mathrm{h}(\mathrm{t})$. Hence, $\mathrm{u}=\mathrm{u}(\mathrm{t})$. Total utility from life years increases at the decreasing rate.

In the absence of disease, the utility function takes the following form

(2) $u=A t^{\alpha}$

where $\mathrm{A}$ is a constant and $\alpha<1$ is the parameter determining the rate of increase of $U$. Figure 2 depicts the utility function.

The total utility increases, at least up to $\mathrm{T}$ year. The value of $\mathrm{T}$ is determined at the highest life expectancy of population in a society (say, 80 years). One can argue that, given the retirement year as $t^{c}$, the utility curve will be oabcu ${ }_{1}$ since total net income will remain constant at $\mathrm{t}^{\mathrm{c}}$. But we have to take into account the other determinant of utility: health status (h) of the member. Utility of $h$ increases at the constant rate as $t$ increases, at least up to $\mathrm{T}$, and this makes the u curve upward- sloping.

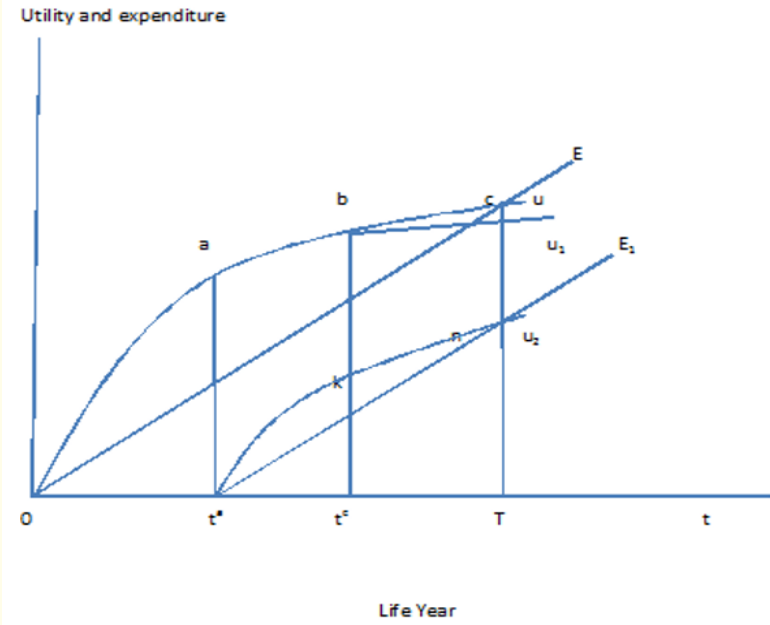

Figure 2: Equilibrium for healthcare.

Now assume that a disease attacks a child in the first year of his life, seriously threatening his life. If appropriate healthcare is not used, all of $\mathrm{T}$ years of his life will be lost and the u curve will cease to exist. If the household receives the required amount of healthcare it will have to incur cT amount of expenditure, as shown along the expenditure curve. The household is saving T years of life and getting cT amount of utility along the $\mathrm{u}$ curve by spending $\mathrm{cT}$ amount of expenditure. Hence, cT amount of money can be considered as the total utility of a full life. Once the utility of all life years is obtained, the utility function can be estimated in the following manner: first, obtain from household survey or assume a realistic value of $\alpha$; then find the value of A solving Eq. (1) and get the utility function. Using the estimated u function, it is possible to obtain the value of utility for any $t$.

If member of the household is an employed adult, aged more than 18 years, and a deadly disease occurs to him in $t^{\text {a }}$ year, use of adequate healthcare will save $\mathrm{T}-\mathrm{t}^{\mathrm{a}}$ years for him. To show equilibrium, we now need to shift the origin from 0 to $t^{\text {a }}$ year. The utility function will be $t^{\mathrm{a}} \mathrm{kn}$ and expenditure line is $t^{\mathrm{a}} \mathrm{n}$. If the amount of healthcare expenditures for the person is same as that for the child as mentioned above, the equilibrium is determined at point $c$. If, however, the amount of health care expenditure for the adult person is lower, such as shown by the line $t^{\mathrm{a}} \mathrm{n}$, then the utility function is $\mathrm{t}^{\mathrm{a}} \mathrm{k} \mathrm{n}$ and equilibrium is at $\mathrm{n}$. It may be noted, however, that the utility curve can be steeper for the adult than for the child because disease will cause loss of actual income for him while it will cause loss of potential income for the child. The household may value actual income more.

In any case, equilibrium is determined at the point where total utility is equal to total expenditures for healthcare.

However, in many cases it is likely that for a sick person healthcare and associated expenditures are exogenously determined and 
remain constant for all life years (at constant prices), so that the amount is same for child, adult and elderly. Then, in Figure 2 the amount of expenditure is cT for both child and old man, although the amount of utility obtained by the child is much higher than for the old man. In those cases some negative amount of what Marshall called rent will ensue to the old man.

For each member, every household has a utility function like the $\mathrm{U}$ curve in Figure 2.The u curve exists in the absence of disease to the member. If disease occurs to the member, the household will lose utility in three ways: loss of utility of health status, loss of income, and increase in expenditure. It can be assumed that the amount of utility from $t$ is same for all life years and for all individuals, irrespective of age, caste/creed, or status. There should be no discrimination of the value of health among the people; it is same for the child and the old, rich and poor, white and black, powerful and powerless. If $b$ denotes utility of one life year with good health, then utility function for health is:

(3) $u_{1}=b t ; b>0$

The utility curve will be a straight line passing through the ori$\operatorname{gin}^{1}$ as shown in Figure 3.

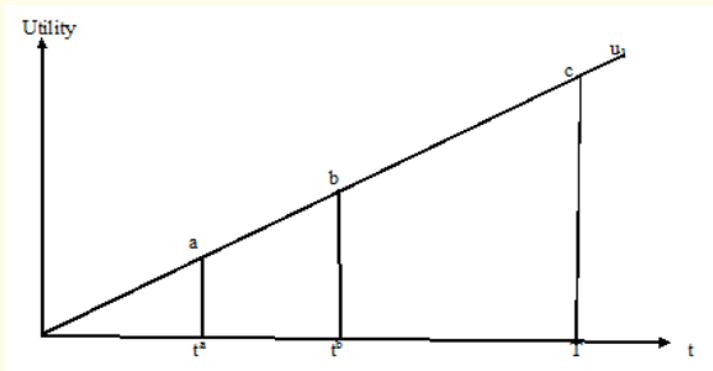

Healthylife year of an individual ( $t$ )

Figure 3: Total utility of health years of an individual.

The total life time of the individual is assumed T years.

For a household with a sick person, the main motive is to obtain the entire amount of appropriate healthcare needed to save the life and life years of the sick person, rather than to maximize consumer's surplus. If the person is attacked by a deadly and costly disease at a very early age, say at age 1 , and use of healthcare fully recovers him and saves $80+$ years of his life, the amount of healthcare and associated expenditures can be considered equal to the value of utility to be derived from health during life time (T years). If $\hat{E}$ denotes the expenditures incurred to immediately recover from the disease, then, given the linear utility line, $\frac{\hat{E}}{T}-\lambda$ is the amount of utility of a healthy year.
Using $\lambda$, it is possible to calculate the monetary value of the health effect of a disease. In Figure 1, if the person becomes ill in year $t^{\mathrm{a}}$ and dies instantaneously, the household will lose T-t $\mathrm{t}^{\mathrm{a}}$ years of life and $u=\lambda\left(T-t^{a}\right)$ amount of utility. If the person suffers from $t^{a}$ to $t^{\mathrm{b}}$ years and then fully recovers the loss of life years (LYs) will be

(4.1) LYs $=\mathrm{s}(\mathrm{tb}-\mathrm{ta})$

Where $s$ is the parameter showing the severity level of the disease. $s$ can be measured on a 10- point scale such that $s=0$ when the individual has good health, $s=1$ when he is clinically dead and any intermediate value between 0 to 1 indicates low, moderate and high levels of severity. The loss of utility (LOU) or health effect of the disease will be

(4.2) $\mathrm{LOU}=\lambda \mathrm{s}\left(\mathrm{t}^{\mathrm{b}}-\mathrm{t}^{\mathrm{a}}\right)$

It is also possible that the individual will suffer from $t^{\mathrm{a}}$ to $\mathrm{t}^{\mathrm{b}}$ year and then die in the tb year so that he will have both morbidity and mortality. In that case total life years lost will be

(4.3) $L Y s=s\left(t b-t^{a}\right)+\left(T-t^{b}\right)$

The first parenthesized term on the right hand side measures morbidity component and the second term the mortality component of loss of years. The total loss of utility, the effect on health, is:

(4.4) $\mathrm{LOU}=\lambda \mathrm{s}\left(\mathrm{t}^{\mathrm{b}}-\mathrm{t}^{\mathrm{a}}\right)+\lambda\left(\mathrm{T}-\mathrm{t}^{\mathrm{b}}\right)$

\section{Economic effect: loss of productivity}

The second component of utility depends on income. The utility of income function is likely to take the following specific form $\mathrm{u}_{2}=A \mathrm{y}^{\mathrm{a}}$

Where $\mathrm{y}=$ income, and $\mathrm{A}>1$ and $\mathrm{a}<1$ are parameters. The marginal utility of money falls as income increases.

Income of an individual/household has in turn two components: asset income and labor income. An individual of any age can have asset income earned through inheritance at the early age and through both inheritance and past savings in the later ages. Labor income accrues to the individual only during the middle years of his life, mostly between 18 years and 65 years. The income possibility curve is shown in the following diagram.

Between $\mathrm{t}^{18}$ and 0 years, the individual has only asset income and the amount is usually low. y rises fast after $\mathrm{t}^{18}$ and continues to increase till $\mathrm{t}^{\mathrm{c}}$ years due to the addition of labor income to asset income. Beyond $\mathrm{t}^{\mathrm{c}}$ year, labor income becomes zero or negligible and total income falls.

\footnotetext{
${ }^{1}$ One can argue that the utility curve $\mathrm{u}_{1}$ should start from the point of -1 along the $\mathrm{x}$-axis because the household starts getting utility from the child's health from the time when it is conceived in mother's womb. We are ignoring this aspect related to the intercept of the curve assuming that child's health can be considered a part of mother's health till it is born (period 0).
} 


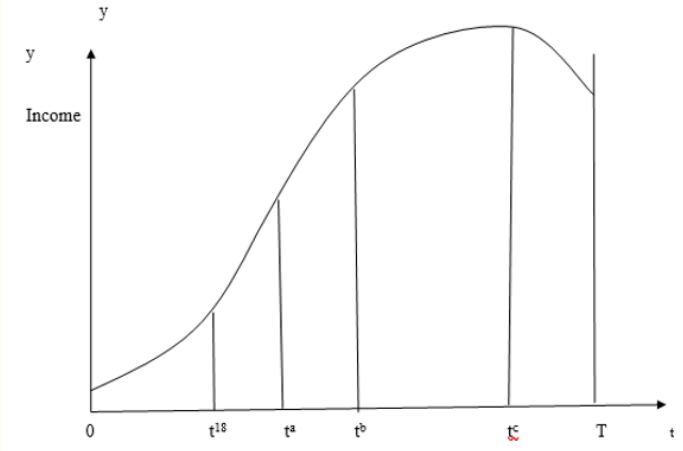

Figure 4: Income possibility curve of an individual.

Where $\mathrm{t}=$ life years

The occurrence of a disease affects labor income. The labor income is the outcome of the individual's economic productivity and, hence, loss of labor income can be called loss of productivity. A disease will cause loss of productivity. There will be productivity loss during the disease period since the sick person will not be able to devote his full labor (or any labor) to production. The amount of this loss will depend on the duration and severity of disease. In Figure 3 if the person becomes sick at age $t^{a}$ and suffers up to age $\mathrm{t}^{\mathrm{b}}$ with the severity level $\mathrm{s}$, then the amount of productivity loss (LOP) is

(5) $(\mathrm{LOP})_{1}=\mathrm{w} \mathrm{s}\left(\mathrm{t}^{\mathrm{b}}-\mathrm{t}^{\mathrm{a}}\right)$

Where $\mathrm{w}=$ annual wage income of the individual.

Second, if the person dies at the age of $t^{b}$, then his household will lose all labor income for the period between $t^{c}$ and $t^{b}$. This productivity loss due to mortality will be

(6) $(\mathrm{LOP})_{2}=\mathrm{w}\left(\mathrm{t}^{\mathrm{c}}-\mathrm{t}^{\mathrm{b}}\right)$

Eq.(7) combines the productivity loss resulting from both morbidity and mortality

(7) $\mathrm{LOP}==\mathrm{ws}\left(\mathrm{t}^{\mathrm{b}}-\mathrm{t}^{\mathrm{a}}\right)+\mathrm{w}\left(T-\mathrm{t}^{\mathrm{b}}\right)$

It should also be noted that income loss here refers to loss of both actual and potential income. Therefore, disease of a child also will cause income loss. In the case of a child's disease, only the first component of income loss, the direct productivity loss, will not apply; the other components will remain almost same. The income loss equation for the sick child (before 18 years of age) will be

(8) $(\mathrm{LOP})_{3}=\hat{w}\left(\mathrm{t}^{\mathrm{c}}-\mathrm{t}^{18}\right)$

if the child recovers from the disease before $t^{18}$. Here $\hat{w}$ is the potential wage rate for the child-the rate that he is expected to earn during his work years. It is assumed here that $w$ is equal to the current market wage rate and $\hat{w} \leq \mathrm{w}$ since the disease can cause some disability even if he recovers. If the child dies before $\mathrm{t}^{18}$ years, then

(9) $(\mathrm{LOP})_{4}=\hat{w}\left(\mathrm{~T}-\mathrm{t}^{18}\right)$
Given $\mathrm{u}_{2}=A y^{\mathrm{a}}$, as noted in the beginning of the sub-section, the loss of utility caused by the disease will be

(10.1) $(\mathrm{LOU})_{1}=\mathrm{A}\left[\text { w.s. }\left(\mathrm{t}^{\mathrm{b}}-\mathrm{t}^{\mathrm{a}}\right)\right]^{\alpha}$

for the person who recovers from the disease, and

(10.2) $(\mathrm{LOU})_{2}=\mathrm{A}\left[\mathrm{w} \cdot \mathrm{s}\left(\mathrm{t}^{\mathrm{b}}-\mathrm{t}^{\mathrm{a}}\right)+\mathrm{w}\left(T-\mathrm{t}^{\mathrm{b}}\right)\right]^{\alpha}$

for the person who dies after suffering for some years.

Economic effect: medical and non-medical expenditures

After occurrence of disease to a member, the household has to incur expenditures to receive healthcare. It has also to spend money for traveling to facility, food and lodging of the sick person and the attendants during stay at or near facility etc. It is plausible to assume that the amount of expenditures is high in the beginning of the disease period and it gradually falls over time. It is also very likely that some expenditure have to be incurred for some more time after the individual recovers from the episode. In addition, some expenditure may be financed through borrowing, and expenditures in the form of repayment of loan are incurred for some more years even after recovery of the sick person.

Figure 4 depicts the behavior of medical and non-medical expenditures (E). It may be noted that the amount of expenditures includes both the amount incurred by the household and the amount incurred by the society.

The expenditure can also be considered as negative income. Before disease, $\mathrm{E}=0$ and the expenditure line coincides with the $\mathrm{x}$-axis. After a disease occurs at $\mathrm{t}^{\mathrm{a}}$, amount of expenditure is $\mathrm{t}^{\mathrm{a}} \mathrm{E}$. $\mathrm{EE}^{1}$ line shows the trend of expenditure (as shown in Figure 2).

\section{Total effect of a disease (VODE)}

The total effect of a disease, combining health effect, income loss and expenditures, can be neatly shown in Figure 5.

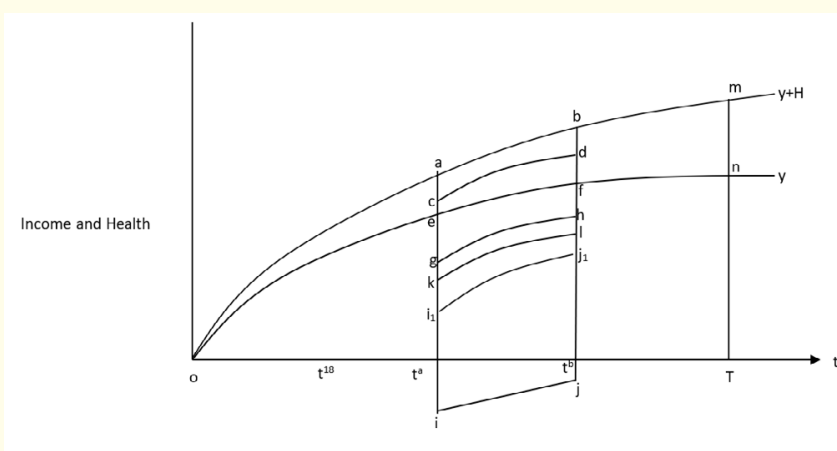

Health Year

Figure 5: Total effect of disease.

The figure shows all components of disease effects. Y curve shows the income path in the absence of any disease. $\mathrm{Y}+\mathrm{H}$ curve shows the time path of income and money value of health $(\mathrm{H})$ in 
the absence of disease. After occurrence of disease, a large amount of value will be lost from the $\mathrm{Y}+\mathrm{H}$ curve. Moreover, there will be a time path of expenditure, as shown by ij curve below the $\mathrm{x}$-axis. We assume that disease occurs at ta year along the horizontal axis and ends at tb. There will be two alternative effects on money value of health $(\mathrm{H})$, as measured by the vertical distance between $\mathrm{Y}+$ $\mathrm{H}$ curve and the $\mathrm{Y}$ curve. If there is only morbidity, $\mathrm{h}$ will take the values along the cd curve and the area between ab and cd curves is the loss of h. Due to morbidity income curve will shift from ef to gh. The amount of expenditures is shown by the vertical distance between the horizontal axis and ij curve up to tb and this amount will be same for morbidity alone and both morbidity and mortality of the sick person. The same expenditure is also represented by the i1j1 in the positive quadrant. In order to obtain the total effect of morbidity, the area between cd and ef curves (the amount of health that the person possesses during the disease period) is deducted from the area between $a b$ and $i 1 j 1$ curves. The net effect of morbidity becomes the area between ab and $\mathrm{kl}$ curves.

If the person dies, then the mortality effect will be the entire area between bm and tb T curves. The combined effect of morbidity and mortality will be: aklb $+\mathrm{b}$ tb Tm areas. The figure clearly shows that the magnitude of total effect of a disease is very large, especially if the person meets death due to disease.

\section{Loss of utility due to disease}

All the three effects of a disease can now be combined and the total loss of utility caused by the disease can be computed. Since expenditure is negative income and both income and expenditures are measured on the same scale of money, the co-efficient A and $\alpha$ of the utility function $u=A y^{\alpha}$ are same for both. Hence, expenditures can be added to income loss in one function to obtain the total economic loss. Denote $\mathrm{L}_{11}$ as the loss of utility due to effect of disease on health for the sick person having only morbidity, $L_{12}$ as the loss of utility due to the same for the person having both morbidity and mortality, $\mathrm{L}_{21}$ as the utility loss due to economic effect (loss of income and incurring of expenditures) for morbidity, and $\mathrm{L}_{22}$ as the utility loss due to economic effect for both morbidity and mortality. Then, we can write:

$\mathrm{L}_{11}=\lambda \mathrm{s}\left(\mathrm{t}^{\mathrm{b}}-\mathrm{t}^{\mathrm{a}}\right)$

$\mathrm{L}_{12}=\lambda$.s. $\left(\mathrm{t}^{\mathrm{b}}-\mathrm{t}^{\mathrm{a}}\right)+\lambda\left(\mathrm{T}-\mathrm{t}^{\mathrm{b}}\right)$,

$\mathrm{L}_{21}=\mathrm{A}\left[\right.$ w.s. $\left(\mathrm{t}^{\mathrm{b}}-\mathrm{t}^{\mathrm{a}}\right)+\mathrm{E}^{\alpha}$

and

$\mathrm{L}_{22}=\mathrm{A}\left[\mathrm{w} \cdot \mathrm{s} .\left(\mathrm{t}^{\mathrm{b}}-\mathrm{t}^{\mathrm{a}}\right)+\mathrm{w}\left(\mathrm{T}-\mathrm{t}^{\mathrm{b}}\right)+\mathrm{E}\right]^{\mathrm{\alpha}}$

Which follow from Equations (4.1), (4.3),(10.1), and (10.2),respectively; the only change made in the above set of equations is that $\mathrm{E}$ has been added in the equations of $\mathrm{L}_{21}$ and $\mathrm{L}_{22}$.

Hence, total utility loss for morbidity is:

(11a) $\mathrm{L}^{\mathrm{m}}=L_{1}^{m}+L_{2}^{m}=\lambda . s .\left(\mathrm{t}^{\mathrm{b}}-\mathrm{t}^{\mathrm{a}}\right)+\mathrm{A}\left[\mathrm{w} \cdot \mathrm{s}\left(\mathrm{t}^{\mathrm{b}}-\mathrm{t}^{\mathrm{a}}\right)+\mathrm{E}\right]^{\alpha}$
And that for the sick person having both morbidity and mortality is: $(11 \mathrm{~b}) \mathrm{L}^{\mathrm{d}}=L_{1}^{d}+L_{2}^{d}=\lambda \cdot \mathrm{s}\left(\mathrm{t}^{\mathrm{b}}-\mathrm{t}^{\mathrm{a}}\right)+\lambda\left(\mathrm{T}-\mathrm{t}^{\mathrm{b}}\right)+\mathrm{A}\left[\mathrm{ws}\left(\mathrm{t}^{\mathrm{b}}-\mathrm{t}^{\mathrm{a}}\right)+\mathrm{w}\right.$
$\left.\left(\mathrm{T}-\mathrm{t}^{\mathrm{b}}\right)+\mathrm{E}\right]^{\alpha}$

Equations (11a) and (11b) measures the total effects of a disease in terms of utility loss. Both equations have subjective and objective versions. In the subjective version, the amount of disease effects can be derived in terms of utility loss. In Eq. (11a), the first term on the right hand side is the effect on health and is objectively measurable since the value of $u$ is empirically determined. From the second component we obtain

(12a) $\left(\frac{L_{2}^{m}}{A}\right)^{\frac{1}{\alpha}}=w s\left(t^{b}-t^{a}\right)+\stackrel{\Lambda}{w}\left(t^{c}-t^{b}+E\right)$

If we know the utility of the economic effects of disease and the value of subjective coefficients $A$ and $\alpha$, we can obtain the total value of disease effects (right hand side). Or, if we compute the values of the terms on the right hand side, which contain the variables and parameters that are fully objective and more easily observable and measurable, we can obtain the value of disease effects which cause the utility loss. The same is also true for Eq. (11b), which can be written as

(12b) $\left(\frac{L_{2}^{d}}{A}\right)^{\frac{1}{\alpha}}=w s\left(t^{b}-t^{a}\right)+w\left(T-t^{b}\right)+E$

The variable and parameters in the right hand side are objective in nature and are easily measurable.

It may be noted that the utility function of health and income/ expenditure, though contain high degree of subjective values, can be estimated empirically, but it requires a good amount of time and efforts to do so.

More importantly, that is not necessary to compute the value of utility to assess the disease effects. We can bypass the complicated task of measuring utility and obtain the money value of the disease effects (VODE) by computing the right hand side of the two alternative equations:

(13) $\operatorname{VODE}_{1}=\lambda s\left(t^{\mathrm{b}}-\mathrm{t}^{\mathrm{a}}\right)+\mathrm{ws}\left(\mathrm{t}^{\mathrm{b}}-\mathrm{t}^{\mathrm{a}}\right)+\mathrm{E}$

Which follows from Eqs. (11a) and (12a). The equation measures the money value of total effect of disease for the morbidity case. On the other hand,

(14) $\operatorname{VODE}_{2}=\lambda s\left(t^{\mathrm{b}}-\mathrm{t}^{\mathrm{a}}\right)+\lambda\left(\mathrm{T}-\mathrm{t}^{\mathrm{b}}\right)+\mathrm{ws}\left(\mathrm{t}^{\mathrm{b}}-\mathrm{t}^{\mathrm{a}}\right)+\mathrm{w}\left(\mathrm{T}-\mathrm{t}^{\mathrm{b}}\right)+\mathrm{E}$

Which follows from Eqs.(11b) and (12b). This equation measures the money value of total effect of a disease when the sick person has both morbidity and mortality.

The following figure clearly exhibits the loss of utility/wellbeing caused to a household by a disease of its member. Along the $\mathrm{x}$-axis 
life years $(t)$ of the individual and along the $y$-axis amount of wellbeing are shown. The household member is expected to live for $\mathrm{T}$ years. If he never suffers from any disease, the time path of his utility is represented by $\mathrm{U}_{0}$ curve, which corresponds to the $\mathrm{y}+\mathrm{H}$ curve in Figure 5. Then, assume that he falls sick at the age of $t^{\mathrm{a}}$ and suffers till $t^{\mathrm{b}}$, he will lose labor income and his utility will decline due to income effect, and the utility curve will become $U_{1}$ curve. The vertical difference between $U_{o}$ and $U_{1}$ curves shows the utility loss caused by income effect of the disease. Medical and non-medical expenditures caused by the disease will further reduce utility, to the curve $U_{2}$, so that the difference between $U_{1}$ and $U_{2}$ measures the utility loss caused by the expenditure effect of the disease. Finally, after deducting the utility loss caused by the effect on health we get $\mathrm{U}_{3}$ curve. The entire shaded area constitutes the loss of utility due to the disease.

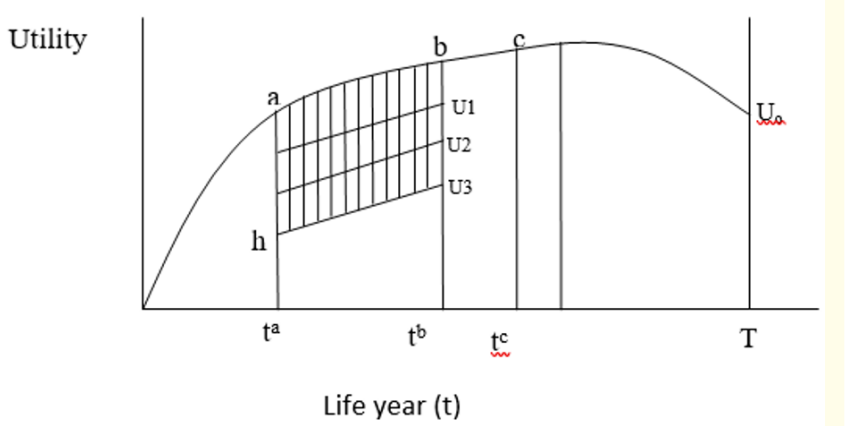

Figure 6: Total loss of well-being caused by a disease.

It may be noted here that the utility loss due to the disease effects has been shown in this figure in a slightly different way from that in Figure 5 for the sake of simplicity and better exposition. We have shown first the effect which endures for a longer period and then that for a shorter period. Hence, utility loss caused by income loss is shown first, then the same by expenditure effect is shown, and finally that by effect on health.

The same curve can be used also to show the loss of utility for the individual if he dies in $t^{b}$ after suffering for $t^{\mathrm{a}}-\mathrm{t}^{\mathrm{b}}$ period. The individual then has both morbidity and mortality. The total utility loss will be the sum- total of the areas $a \mathrm{~h}_{3} \mathrm{~b}$ and $\mathrm{b} \mathrm{t}^{\mathrm{b}} \mathrm{T} \mathrm{u}$. The loss of utility is huge for the death cases.

\section{Operational method of estimating money value of disease effects}

It is evident from the preceding section that estimation of utility loss caused by a disease is not very easy, nor is it necessary to obtain the money value of the disease effects because the subjective value of utility has its objective equivalents. Estimation of money values of the components of disease effect will yield the money value of disease effects. At the same time it will give the money value of utility loss if the values of the coefficients of money (A and $\alpha$ ) are given. It is now possible to derive an operational method of estimating the disease effects by way of operationalizing the objective components of the effects.

As shown in the earlier section, a disease causes utility loss through three effects: income effect, expenditure effect, and effect on health. Again, for each type of effect the magnitude of effect of mortality will be different from that of morbidity.

We define $\mathrm{t}=$ health year and $\mathrm{t}=1,2,3, \ldots \ldots \ldots ., \mathrm{t}^{\mathrm{a}}, \ldots \ldots \ldots ., \mathrm{t}^{\mathrm{b}}, \ldots \ldots \ldots ., \mathrm{t}^{\mathrm{c}}$ ,.......,T, where $t=1$ is the year of birth, $t^{\mathrm{a}}$ is the year of onset of disease, $t^{b}$ is the year when the sick person either fully recovers from or dies due to the disease, $t^{\mathrm{c}}$ is the year of retirement from employment, and $\mathrm{T}$ is the year of normal death. The other notations to be used here can be restated as follows.

$\mathrm{Y}=$ Annual income being or to be earned by the sick person in the absence of disease

$\mathrm{M}=$ Annual income accruing to the sick person after disease,

$\mathrm{E}=$ Medical and non-medical expenditures for healthcare,

$\lambda=$ Permissible market value of utility of one healthy year,

$\mathrm{t}^{\mathrm{a}}=$ Year of onset of disease,

$\mathrm{t}^{\mathrm{b}}=$ Year of recovery or death,

$\mathrm{t}^{\mathrm{b}}-\mathrm{t}^{\mathrm{a}}=$ Duration of disease in years

$\mathrm{t}^{\mathrm{c}}=$ Retirement year,

$\mathrm{T}=$ Maximum expected life years,

$\bar{t}=$ Year when normal working life begins $\left(18^{\mathrm{th}}\right)$,

$\mathrm{Y} \bar{t}=$ Per capita GDP in $\bar{t}$,

$\mathrm{g}=$ Annual growth rate of GDP,

$\mathrm{r}=$ Rate of discount.

We now move to discuss the operationalization method of estimating the of disease effects that have been explained in the earlier section.

\section{Income loss due to disease}

Denote $y=$ annual income that the individual would have earned in the absence of disease, $\mathrm{M}=$ annual income that he will earn (if any) during the disease periods. For a sick individual who fully recovers from the disease in $t=t^{b}$, the present value of productivity loss (or loss of labor income) estimated at $\mathrm{t}=\mathrm{t}^{\mathrm{a}}$ is

(15a) $y_{\ell}{ }^{1}=\sum_{t=1}^{b} \frac{Y_{t}-M_{t}}{(1+r)^{t}}=\frac{Y_{1}-M_{1}}{1+r}+\frac{Y_{2}-M_{2}}{(1+r)^{2}}+\ldots+\frac{Y_{b}-M_{b}}{(1+r)^{b}}$

Where $r=$ the rate of discount. Here the disease period is $t^{a}$ to $t^{b}$ and the onset year ta is assumed to be 1 and the recovery year $t^{\mathrm{b}}$ is assumed to be $n$. Thus the origin of the time path of health is shifted from the year of birth to the year of onset of disease.

If the sick person suffers from the disease for the $t^{a}$ to $t^{b}$ years and then dies, the person has both morbidity and mortality. The present value of productivity loss for him will be: 
(15b) $y_{\ell}^{2}=\sum_{t=1}^{b} \frac{Y_{t}-M_{t}}{(1+r)^{t}}+\sum_{t=b}^{c} \frac{Y_{t}}{(1+r)^{t}}$

In case the sick person is a child (below 18 years), the household will lose his potential labor income if he dies in childhood. The potential income loss caused to the household by the child's mortality should be considered income loss. The potential income loss will also occur if the child becomes partly or fully disabled. Thus, both formulae 15 (a) and 15 (b) will apply to the child disease case, but the year when income loss will start will be different. In the above formulae the starting year is the year of onset of the disease. But for the child income loss will begin from the year when he is likely to get a job. The possible amount of his annual income will depend on the nature and level of his job. One way of assessing his annual income in future is sum total of average income in an income quintile weighted by probability of entering into that quintile. Thus, the expected annual income of the child is

$y^{e}=\sum_{i=1}^{5} P_{i} \overline{y_{i}}=P_{i} \bar{y}_{i}+P_{2} \bar{y}_{2}+P_{3} \bar{y}_{3}+P_{4} \bar{y}_{4}+P_{5} \overline{y_{5}}$, and $\sum_{i=1}^{5} P_{i}=1$

Where $y^{e}=$ expected annual income, $\mathrm{P}_{\mathrm{i}}=$ probability of getting a job in the $\mathrm{i}$-th income quintile, and $\hat{y} \mathrm{i}=$ average income in the $\mathrm{i}$-th quintile. If the probability is equal in all quintiles, then $y^{\mathrm{e}}$ will be equal to the per capita GDP ( $\hat{y}$ ). If the real per capita GDP grows at the rate of $g$, then the present value of the flow of annual income for the child $\left(\mathrm{y}_{1}^{\mathrm{c}}\right)$ is:

(16) $y_{l}^{c}=\frac{1}{(1+r)^{\bar{t}-t^{a}}} \sum_{t=1}^{42} \frac{\hat{y}_{t}(1+g)^{\bar{t}}}{(1+r)^{\bar{t}}}$

Where $\bar{t}=1$ is the year of getting job (18 years), and $\bar{t}=42$ is the year of retirement, and $\mathrm{t}^{\mathrm{a}} \mathrm{is}$, as in other cases, the age of child when he becomes sick.

On the right hand side of the equation, the second component shows the total income, estimated at the price level of $t=1$ year (or the year when the child will be 18 years), to be earned by the child and the first component is the discount factor used to transform the amount of income of year $t=1$ (or 18 years) into the amount of year $\mathrm{t}^{\mathrm{a}}$.

If the child dies or becomes greatly disabled due to the disease, he will lose the entire flow of potential income, as shown by Eq. (16). The amount is estimated in the year of onset of disease for the 42 working years starting from 18 to 60 years of the child's life. Since $\hat{Y}$ is the per capita GDP in year $\mathrm{t}^{\mathrm{a}}$, the starting year will be the current year $t^{a}$ in estimating the present value.

One can argue that an able bodied adult person earns income and, on the other hand, creates cost for the household and the society-- the cost incurred for his living, and in estimating income loss the amount of cost (C) of living should be deducted from income (y). In that case the net income loss will be much lower. However, for the present moment we assume that living cost is to be incurred for all persons, whether able-bodied or disabled and child or adult, so that it is common for any human being and, hence, can be disregarded in the estimation of income loss.

If the disease occurs to an old man, aged 60+ years, there will be no loss of productivity for him.

\section{Expenditures for healthcare}

The household of the sick person as well as the society at large have to incur medical and some non-medical expenditure to receive healthcare for him. If the disease continues for several years, then irrespective of whether he recovers or dies, the present value of the expenditures (E) will be:

$$
\text { (17) } \sum_{t=1}^{b} \frac{E_{t}}{(1+r)^{t}}=\frac{E_{1}}{(1+r)}+\frac{E_{2}}{(1+r)^{2}}+\ldots \frac{E_{b}}{(1+r)^{b}}
$$

Where $t=1$ when the person becomes sick and $t=b$ when he recovers or expires.

\section{Loss of utility of health}

Three factors determine health effect of a disease: estimated utility $(\lambda)$ of a healthy year of a person, severity level of the disease, and duration of disease.

The amount of well-being loss will be different for the case of mortality from that of morbidity. The amount of loss for morbidity will be

(18a) $\mathrm{H}_{1}=\lambda s\left(\mathrm{t}^{\mathrm{b}}-\mathrm{t}^{\mathrm{a}}\right)$

And the same for mortality (plus morbidity) will be

(18b) $\mathrm{H}_{2}=\lambda s\left(\mathrm{t}^{\mathrm{b}}-\mathrm{t}^{\mathrm{a}}\right)+\lambda\left(\mathrm{T}-\mathrm{t}^{\mathrm{b}}\right)$

Where $t^{\mathrm{a}}$ is the age of the person at the time of onset of disease, $t^{b}$ is the age when he recovers or dies, and $\mathrm{T}$ is the age of normal death.

The parameter $\lambda$ denotes the current market value of utility of health of a sick person. The objective value of the subjective utility can be obtained from observation of the realities in the healthcare market. In Economics the market demand function, which is actually the willingness to pay schedule of the consumers in a period, is very often approximated by the price-quantity relationship observed in the market in an earlier period. The main reason for this is that it is usually very difficult to obtain even in a market, let alone in the absence of the market, the accurate demand function based on the data on consumers' willingness to pay. To get a value of $\lambda$, it is better to depend on the market data rather than on the willingness to pay schedule. The total of the highest expenditures incurred in the current year $\left(\mathrm{t}=\mathrm{t}^{\mathrm{t}}\right)$ by the households and/or the society in a setting (region or country) to receive health care for the old persons (aged over 60 years) suffering from the deadly diseases can be used as the value of total utility that the households 
wanted to obtain from the recovery of the persons. The underlying conditions of the method are: the patients are old, they suffer from any deadly disease, and among them only the persons for whom highest medical expenditures have been incurred should be considered. The condition that the sick persons selected for this purpose should be aged over 60 years is to ensure that the households do not have any consideration for the income loss caused by the disease in making decisions about health care expenditure. The objective of setting the condition that the patients suffer from a deadly disease is to clearly obtain the number of life years that the healthcare to be used is expected to save. The healthcare in this case will avert mortality and the value of $\lambda$ will represent the utility of life years saved; the process of computation will not include calculation of the morbidity years, which involves some amount of ambiguity and subjective judgment of the patients.

It is possible that a large number of persons contract the same or similar diseases and the households of the patients may spend different amounts of money to receive healthcare for them. Among them only the patients for whom the best possible healthcare has been received should be considered. It is assumed here that high expenditure is required for the best quality of healthcare in a competitive market, and that is needed and desired by all of these households, whether they are able to pay or not. Many households are not able to pay for the best quality of healthcare and, worse still, even the amount of total income of many households may be less than the amount needed for the best possible care. As already noted, in a competitive market the demand function for a commodity represents the willingness to pay of the buyers backed by their ability to pay. The equilibrium price is determined at the point of intersection of the demand and supply functions. The equilibrium price is the market price even if there is at least one person to pay that price and other buyers fail to pay that either due to lack of the necessary amount of desire or sufficient ability to pay. That is to say, the situation when only a rich household purchases a high quality healthcare at a very high price and others cannot buy it due to lack of ability to pay does not debar the price paid from being the market price ${ }^{2}$. $\lambda$ can be called the permissible value of utility of health and it differs from the actual utility of health. The underlying idea for using $\lambda$ is simple. The desire for good health and long life years of an individual to him as well to his relatives and society is usually illimitable, and hence the amount of utility of health cannot be made bounded using any finite number such as per capita GDP. At the same time, it is also true that utility of health cannot be limitless in view of the ability of man to pay for attaining or maintaining good health, even when very high, has a limit. The permissible value of utility of health is a compromise: it is not as high as the sky, as is the value of actual utility, and it is not as low as to be captured by the GDP.

Subtracting the age of a person at onset of the disease from the expected life years $\mathrm{T}$, we can obtain the number of life years a household wanted to save. Dividing the total utility by the sum total of life years saved for all persons considered, we can obtain the value of $\lambda$ for a healthy year. The value of $s$ and duration of disease can be obtained based on observation and opinion of the sick individual or his household.

The effects can now be combined to obtain the total effect of disease (TED) in terms of money.

If the disease occurs to an adult and it causes only morbidity, then the value of TED for the sick person is

$$
\text { (19) } \mathrm{V}_{1}=\sum_{t=1}^{b} \frac{Y_{t}-M_{t}}{(1+r)^{t}}+\sum_{t=1}^{b} \frac{E_{t}}{(1+r)^{t}}+\lambda \cdot s\left(t^{b}-t^{a}\right)
$$

Which follows from Eqs. 15 (a), (17), and (18a).* If the disease causes both morbidity and mortality to the adult then the value of TED is

$$
\text { (20) } \mathrm{V}_{2}=\sum_{t=1}^{b} \frac{Y_{t}-M_{t}}{(1+r)^{t}}+\sum_{t=b}^{c} \frac{Y_{t}}{(1+r)^{t}}+\sum_{t=1}^{b} \frac{E_{t}}{(1+r)^{t}}+\lambda \cdot s\left(t^{b}-t^{a}\right)+\lambda\left(T-t^{b}\right)
$$

The method is also applicable when the disease causes morbidity, as it is when there is mortality. However, in the former case, accuracy of the estimate of $\lambda$ will be somewhat lower.

${ }^{2}$ The argument can be illustrated by using the following diagram which represents a competitive market situation. The intercept of the supply curve (SS) is very large due to the high cost of producing a quality healthcare. The equilibrium is at point e. The equilibrium price (Po) is high and equilibrium quantity is low--- only one patient household purchases one unit of healthcare. All other households (corresponding to qoq), who demand healthcare, could not or did not purchase healthcare. Even then, Po is the market price.

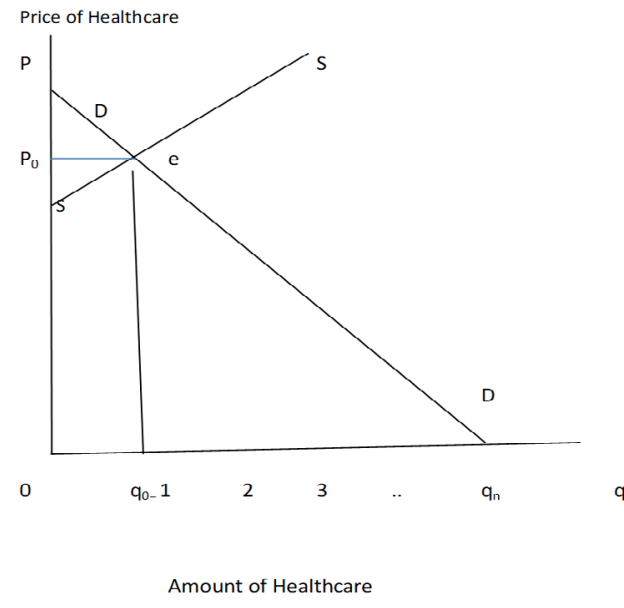

Citation: Sushil Ranjan Howlader. "A Utility-Theoretic Method of Computing Value of Disease Effects for Economic Evaluation of Health Program". Acta Scientific Nutritional Health 3.10 (2019): 54-67. 
Which follows from Eqs. 15 (b), (17), and (18b). For a child, if disease causes only morbidity before his work age, the value of TED is

(21) $\mathrm{V}_{3}=\sum_{t=1}^{b} \frac{E_{t}}{(1+r)^{t}}+\lambda \cdot s\left(t^{b}-t^{a}\right)$

Which follows from Eqs (17) and (18a). If the child dies after suffering from the disease, the value of TED will be for him:

(22) $\mathrm{V}_{4}=\frac{1}{(1+r)^{t}} \sum_{t=1}^{42} \frac{\hat{y_{-}}(1+g)^{\bar{t}}}{(1+r)^{\bar{t}}}+\sum_{t=1}^{b} \frac{E_{t}}{(1+r)^{t}}+\lambda \cdot s\left(t^{b}-t^{a}\right)+\lambda\left(T-t^{b}\right)$

Which follows from Eqs. (16), (17), and (18).The first term on the right hand side has two components. The second component measures the present value of income in $t=t$ year (possible year of joining a job), and the first component converts the second component into the present value in $\mathrm{t}=\mathrm{t}^{\mathrm{a}}$.

If the disease occurs to an old man (aged above 60 years) and it causes only morbidity, the value of TED is

$$
\text { (23) } \mathrm{V}_{5}=\sum_{t=1}^{b} \frac{E_{t}}{(1+r)^{t}}+\lambda \cdot s\left(t^{b}-t^{a}\right)
$$

But if the disease causes both morbidity and mortality to the old man then the value of TED is

$$
\text { (24) } \mathrm{V}_{6}=\sum_{t=1}^{b} \frac{E_{t}}{(1+r)^{t}}+\lambda \cdot s\left(t^{b}-t^{a}\right)+\lambda\left(T-t^{b}\right)
$$

In equation (19), the three terms on the right hand side show the three effects - income, expenditure and health - consecutively. In Eq. (20), the first two terms show the total effect on income, the third term the effect on expenditure, and the last two terms the effect on health. Eq. (21) shows only the effects on expenditure and health; there is no effect on income if disease causes only morbidity to a child. In Eq. (22), the first term is the effect on income, the second term effect on expenditure, and the last two terms effect on health. Eq. (23) shows only the effects on expenditure and health; there is no income effect for the old persons. In Eq. (24), the first term is the effect on expenditure and the last two terms constitute health effect health.

Eq. (20) is the general form of the equation of disease effects. All disease effects, both for morbidity and mortality cases, and for all broad age groups - adult, child and old- can be expressed through this general equation. This equation fully applies to an adult individual who dies after suffering from a disease for some years. If the adult individual recovers from the disease, then the second and last terms are zero, and the equation takes the form of Eq. (19). If the sick person is old and disease causes his death, then the first two terms in Eq. (20) are zero and it becomes same as Eq. (24). If the old man recovers from the disease, then the last term as well as the first two terms is zero and the equation is reduced to Eq. (23). If the sick person is a child who recovers from the disease before the age of entry into job (18 years), then also the first two terms and the last term in Eq. (20) are zero and it takes the form of Eq. (21). However, if the child dies due to the disease, then the first two terms in Eq. (20) are to be replaced by the first term in Eq. (22), so that Eq. (20) becomes same as Eq. (22).

Once the value $\mathrm{V}$ of total disease effects (TED) is obtained using Eq. (25), the value of the loss of wellbeing (LOW) to the household and the society can be estimated.

The value of the loss of utility of health is the same as the last two terms in Eq. (25). In order to estimate the loss of utility due to income loss and expenditure, we have to use the following equation

$\mathrm{L}^{*}=A\left[\sum_{t=1}^{b} \frac{Y_{t}-M_{t}}{(1+r)^{t}}+\sum_{t=1}^{c} \frac{y_{t}}{(1+r)^{t}}+\sum_{t=1}^{b} \frac{E_{t}}{(1+r)^{t}}\right]^{\alpha}$

Where the first two terms in the parenthesis show the income loss and the third term the expenditure. A is the utility coefficient (amount of utility per unit of money), and $\alpha$ is the exponent showing the rate of decline in utility as amount of money increases. Given this, the loss of wellbeing due to the disease is $\mathrm{LOW}=\mathrm{L}^{*}+\mathrm{s}\left(\mathrm{t}^{\mathrm{b}}-\mathrm{t}^{\mathrm{a}}\right)+\left(\mathrm{T}-\mathrm{t}^{\mathrm{b}}\right)$

or

(25) LOW $=A\left[\sum_{i=1}^{b} \frac{Y_{t}-M_{t}}{(1+r)^{t}}+\sum_{t=1}^{c} \frac{y_{t}}{(1+r)^{t}}+\sum_{t=1}^{b} \frac{E_{t}}{(1+r)^{t}}\right]^{\alpha} \lambda \cdot s \cdot\left(t^{b}-t^{a}\right)+\lambda\left(T-t^{b}\right)$

Money Value of total effects of disease and economic evaluation of healthcare interventions

In the health sector, especially in its public component, economic evaluation of an intervention (or of a drug or technique of service provision) is almost obligatory for assessing the level of its economic efficiency. Several techniques have been devised to conduct economic evaluation of healthcare interventions. In any technique the main apparatus used is the ratio of the value of total disease effects averted to the cost of intervention which averts the effects. In the cost-benefit analysis, the intervention is judged worthwhile if the estimated ratio is greater than unity; and the higher is the ratio, the higher is the level of efficiency of the intervention. In the costeffectiveness analysis, the same ratio is computed for more than one intervention and the intervention yielding the higher ratio is considered best among the interventions.

The value of total disease effects (TED) estimated using the above method can be used for economic evaluation. Broadly, there are two types of situations which require economic evaluation: first, when, as already noted, interventions are undertaken to increase use of healthcare, and second, when under the existing system (in the absence of any new intervention) the question arises as to justification of a high amount of expenditure needed for a person to combat a deadly disease. The value of TED can be used in both situations. 
For analyzing efficiency of interventions

The following formula can be used to obtain the evaluation ratio

$$
\text { (26) } \mathrm{V}=\frac{\varepsilon\left[\mathrm{V}_{\mathrm{EH}}+\mathrm{I}_{\mathrm{OY}}+\mathrm{E}\right]}{C}>1
$$

\section{Where}

$\mathrm{V}=$ Value of disease effects per unit of cost of intervention,

$\mathrm{VEH}=$ Value of effect of disease on health of the sick person (to be obtained by using Eq.18 b),

LOY = Loss of income caused by disease (to be obtained by using Eq. 15a or Eq. 15b),

$\mathrm{E}=$ Expenditure for healthcare (actual or required in the competitive market situation) (to be obtained by using Eq. 17),

$\mathrm{C}=$ Cost of the intervention, and

$\varepsilon=$ Efficacy coefficient

The numerator contains the three effects of a disease. The efficacy coefficient is the parameter showing the extent to which the intervention can avert the disease effects. The value of the parameter will vary from o to 1 . If the intervention can fully recover the person instantaneously, then the value of the parameter is 1 ; if not, then the value is less. It is very likely that the value of the parameter will be less than one in most cases because some amount of health years will be lost in the process of use of healthcare--- it takes some time for a patient to complete the doses of drugs and other treatment procedures.

It may be noted that $\mathrm{C}$ in the denominator includes the expenditure for healthcare under the intervention. Evidently, health care expenditure has two separate entities with respect to a disease: disease causes it and, on the other hand, it averts disease. As a result of this duality of its role, it appears both in the numerator and the denominator (as a component of $\mathrm{C}$ ).

\section{For assessing justification of healthcare expenditure}

Sometimes a person is afflicted with a deadly disease and huge expenditure is required for his treatment under the existing system of healthcare provision (there is no new intervention). In such a situation the question can arise whether the large amount of expenditure to be incurred for the patient is economically justified. * The formula to be used to deal with such cases is

(27) $\mathrm{V}_{1}=\frac{\varepsilon\left[\mathrm{V}_{\mathrm{EH}}+\mathrm{L}_{\mathrm{OY}}+\mathrm{E}\right]}{E}>1$

The only difference between Eq. (26) and Eq.(27) is that in the latter $\mathrm{C}$ in the denominator has been replaced by $\mathrm{E}$. The twoway relationship between healthcare expenditure and disease, as noted above, is shown more explicitly here: E has appeared twice-once in the numerator as one effect of the disease and in the denominator as eliminator of the disease.
The formula shows that even if the amount of healthcare expenditure is quite high and the patient does not earn any income, the quality healthcare should be used so long as VEH $>0$ and the value of $\varepsilon$ is close to unity (that is, healthcare is very effective), since even in those cases the condition set in the formula will still be satisfied.

\section{Application of the method}

The method was applied on selected patients through case studies in Bangladesh ${ }^{3}$. The total effects of diseases on selected individuals were estimated using the VODE and DALY methods. Three pairs of patients of cancer were purposively selected from a reputed private hospital in Dhaka: adult (employed), old, and child. Two patients in each pair were chosen in a way that they have almost the same age, disease, duration of disease and household income; the main difference between the two is that one has died and the other survived. The purpose was to assess the effect of mortality on the total effect. In order to clearly obtain the difference in the value of disease effects, the patients who had to spend a large amount of money for healthcare were selected--- the households of the selected patients were relatively rich. The reason for choosing the rich patients was to directly assess the market behavior of the households which have high ability to pay.

The values were calculated in the Bangladeshi currency (Taka). The study patients reported that during the long period of disease the level of severity of the disease---- physical and mental pain and suffering-greatly varied, from very low to very high levels. Given this, we have assumed the moderate level, $s=1 / 2$, as the average value. In computing the value of DALYs averted for the death cases, we have assumed, as in Murray and Lopez [1], the life expectancy as 80 years and the disability weight for cancer was assumed 0.50 , following Solomon., et al. (2015). We have used the simplest version of the DALY method [2]. The summary of the case studies is presented below. For the purpose of comparison, the value of DALYs averted was also computed for each case.

\section{Case 1}

One adult person of Pair1 became sick at 25 years and recovers from the disease at 30 years of his age. The severity level of disease was $s=1 / 2$. He was employed. When he joined the job at age 18, he earned Tk. 360000 per annum. The annual growth rate of his income was $g=15 \%$ and the rate of discount is $r=5 \%$, so that real income grew at the net escalation rate $\mathrm{e}=10 \%$. In the beginning of 25 years of his age, before the onset of disease, his income became $y 1=701538$ Taka. During the disease years, from 25 to 30 years of his age, he could work only for 50 percent of work time since s $=1 / 2$. Hence $\mathrm{M} 1=1 / 2 \mathrm{y} 1$, and $\frac{1}{2} \sum_{t=1}^{5} \frac{Y_{t}-M_{t}}{(1+r)^{t}}=2141480$ taka (assuming that $\mathrm{y}$ was growing at $\mathrm{g}=15 \%$ ). The household and the government (through the public sector health facilities) spent Tk. 50, 000 in each of the five years, so that $\sum_{t=1}^{5} \frac{E_{t}}{(1+r)^{t}}=227297$ Taka.

\footnotetext{
${ }^{3} \mathrm{~A}$ large survey has been undertaken to estimate the value of disease effects using the VODE and DALY methods. The survey is yet to be completed. The results of the survey will be presented in a forthcoming paper.
} 
He had fallen sick in 2008 (when he was 25 years old). In that year in the whole country three highest amounts of expenditures for healthcare incurred for three patients, aged 66 years, 70 years and 75 years were Tr. 1500000, 90000, and 1200000 respectively. The value of $\lambda$ is then

$\lambda=\frac{1500000}{(80-66)}+\frac{900000}{(80-70)}+\frac{1200000}{(80-75)}=$ TR 120690.

Each denominator of each term (on $\mathrm{r} h \mathrm{~s}$ ) shows the number of years saved for the patient. Hence, the total loss of wellbeing due to the disease, following Eq. (19), was *:

$\mathrm{V} 1=2141480+227297+(120690 \times 1 / 2 \times 5)=2670502$ Taka.

On the other hand, the value of DALYs averted was

Value of DALYs averted = (number of days suffered) (disability weight) (Per capita GDP in 2014)* $=(2.5) 83000$ Taka $=207,500$ Taka.

Case 2

The other adult person of Pair 1 suffered from 25 to 30 years of his age and then dies. Other things were more or less same as in case 1. As shown in Eq. (20), the loss of his income due to morbidity was 2141480 , and the same due to mortality was $\sum_{t=t^{b}}^{t^{c}} \frac{y_{t}}{(1+r)^{t}}=185851075$ Taka

Where y grows at $\mathrm{g}=15 \%$ per annum and $\mathrm{t}_{\mathrm{c}}$ is the retirement year, amount of healthcare expenditures was 227297, the loss of utility due to morbidity was 301725 , and the same due to mortality was $120690 \times(80-30)=6034500$. The total wellbeing loss was V2 = 194556077 Taka

The money value of DALYs averted was (number of days suffered). (disability coefficient). GDP per capita in $2014=(5.1 / 2+$ 50). $83000=4,357,500$ Taka.

\section{Case 3}

One sick person of Pair 1 was an old man who became sick at 70 and recovered at 75 , then, other things remaining as above, the total wellbeing loss, following Eq. (23), was V3 = 227297 + (120690 $\times 1 / 2 \times 5)=2670502$ Taka. The value of DALYs averted was (2.5) $83000=207,500$ Taka.

\section{Case 4}

The other old man of the same pair became almost at 70 and died at 75. Then, following Eq. (24), loss of wellbeing was

V4 = $227297+(120690 \times 1 / 2 \times 5)+[120690 \times(80-75)]=1132472$ Taka.

In this case, the value of DALYs averted was $(2.5+5) .83000=$ 622,500 Taka.
Case 5

If the above child dies due to the disease at 15 , then, following Eq. (22), the loss of wellbeing was:

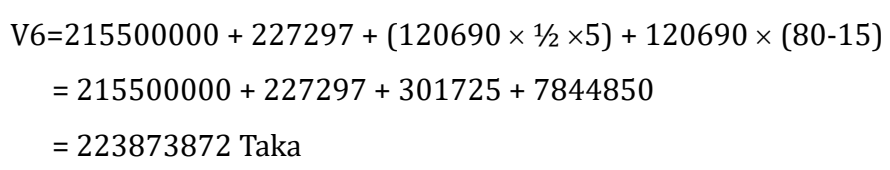

The value of DALYs averted was $(2.5+65) .83000=5,602,500$ Taka.

It is evident from the tables that loss of productivity, actual or potential, is the largest component of the value of disease effects (VODE) to the relevant individuals, followed by mortality caused by the disease. It also clearly appears that the value of the total effect of disease (VODE) is several times higher than the value of DALYs ${ }^{4}$.

\section{Discussions and Conclusion}

Estimation of the money value of disease effects is extremely necessary for conducting economic evaluation of a health program by way of comparing the benefit with the cost of the program. The popular techniques of economic evaluation such as DALYs and QALYs capture in the measure only the effect of a disease on health and not the economic effects, and they do not estimate the money value of even the health effect. The measure described in the paper (V0DE measure) has a number of advantages. The main advantage is that it captures in one estimate all effects of a disease and, more importantly, it obtains the money value of all effects of that. The VODE measure is truly based on the utilitarian approach and can be appropriately considered as a technique of cost-utility analysis. The technique requires a small amount of data and it requires data only on objective variables. Its dependence on the data on subjective variables such as perception of experts or of consumers is minimum. The measure is based on only a few assumptions and none of the assumptions is too unrealistic. The measure is applicable for all types of diseases and for age groups of patients. The VODE captures all the three types of effects: income loss, expenditures, and effect on health and all using the objective market prices. Use of the VODE method can obtain the estimate of the loss of utility caused by the disease, as well.

The method can easily be used for economic evaluation of a health program and its results are very likely to justify even a large investment aimed at eradicating or combating the diseases which contract low number of people and cause low mortality but high morbidity (such as HIV/AIDs). The DALY method underestimates the benefits of a healthcare program and likely to show the programs, which are found effective and efficient to combat the disease/condition, as economically nonviable and unacceptable, posing serious problems for policy makers and donor agencies to support those. An example is cited here. An HIV prevention

\footnotetext{
${ }^{4} \mathrm{~A}$ variation of the DALY method proposes that program cost should be compared with the amount equal to 3 times per capita GDP (Samuel., et al. 2009). However, it is difficult to find a theoretical basis of the suggestion and, hence, not used here
} 
intervention was introduced in 1998 in Bangladesh. Even after implementation of the intervention, the prevalence had increased among the male injectable drug users (IDUs) in Dhaka city. In this situation the need for continued implementation of the effective interventions to combat the threat of the epidemic was felt by the policy makers. A study was undertaken to estimate the impact of possible interventions on reduction of harm among the people of Dhaka who inject drugs, and then conduct the cost - benefit analysis to assess the worthiness of investment in the interventions. Five alternative scenarios of targets were considered for seven drugusing client groups [3,4]. Using the DALY method the benefit - cost ratios of the scenarios were computed. The ratios were marginally greater than unity for only three scenarios and less than that for the other two [5]. But experiences in the neighboring countries including Thailand and India clearly suggested that all scenarios were very effective and financially viable options for rapidly reducing the prevalence of the condition. The results of economic evaluation discouraged the funding agencies to support the intervention. A closer analysis revealed that there were three reasons for the benefit cost -ratios obtained through use of the DALY method being not quite acceptable: DALY method measures only one effect of disease; it attaches very high emphasis on mortality - mortality caused by the HIV/AIDS is low; and expenditure for health care has been placed in the denominator as a component of program cost, although it is one of the economic effects of the disease and should also be put as an item in the numerator. Use of the VODE method changes implications, mainly because it captures all effects of disease/condition. Data on productivity loss and expenditures were not available. Only the health effect of the intervention under different scenarios was computed. It was found that the benefit of health effect alone is much higher than cost, and the benefit- cost ratios are greater than those obtained by the DALY method. The ratios will be several times higher if we can include the value of economic effects in the benefit of averting the condition.

The VODE measure has certain demerits too. The method of computing the value of utility coefficient $\lambda$ is less than perfect and the value severity of disease requires more intensive observation and information on the perception of the patients over the entire duration of disease. The perception of the patients is greatly subjective and may not always truly reflect the reality. For the child, it is necessary to assess the potential annual income and the assessment is to be based on several assumptions which may not be found entirely true in reality. Furthermore, the life year of a person yields not only income, as is assumed here and in other measures, but also generates cost---- cost of his living borne by the household and the society. Instead of gross income (y), the net income ---income minus cost--- can be considered. In that case the amount of income loss will be somewhat lower (by about 25 to 30 percent) [6-43].

\section{Bibliography}

1. Murray CJL and Lopez Ad. "Global Comparative Assessment in the Health Sector". Geneva, World Health Organization (1994).
2. WHO. WHO methods and data sources for global burden of disease estimates 2000-2011, Department of Health Statistics and Information Systems, Geneva (2013).

3. Habib SE., et al. "Assessment of Impact of Harm Reduction Interventions among People Who Inject Drugs (PWID) in Dhaka City, Report. Dhaka: Ministry of Health and Family Welfare, Directorate General of Health Services, NASP (2011).

4. National AIDS/STD Program. "National AIDS statistics unveiled on International AIDS Day. Dhaka: Ministry of Health and Family Welfare". Directorate General of Health Services, NASP (2013).

5. Howlader SR. Economic Analysis of Harm Reduction Interventions, Draft Report as a part of the study for the Harm Reduction Project Dhaka: Ministry of Health and Family Welfare, Directorate General of Health Services, NASP (2011).

6. Anand Sudir., et al. Journal of Health Economics 16 (1997): $1-128$.

7. Baltussen Rob., et al. "Balancing efficiency, equity and feasibility of HIV treatment in South Africa-development of programmatic guidance". Cost effectiveness and resource allocation 11.1 (2013): 26.

8. Bechu N. "The Impact of AIDS on the Economy of Families in Cote d' Ivoire: Changes in Consumption among AIDS-Affected Households". Washington, DC: World Bank. Confronting AIDS: Public Priorities in a Global Epidemic (1997).

9. Croft RA and Croft RP. "Expenditure and loss of income incurred by tuberculosis patients before reaching effective treatment in Bangladesh". International Journal of Tuberculosis and Lung Disease 2 (1998): 252-254.

10. DFID. "Better Health for Poor People. International Development Target Strategy Paper. London". Department for International Development (1999).

11. Ensor T and San PB. "Access and payment for health care: the poor of Northern Vietnam". International Journal of Health Planning and Management 11 (1996): 69-83.

12. Ettling MB and Shepherd DS. "The economic cost of malaria in Rwanda”. Tropical medicine and parasitology 42 (1991): 214218.

13. Sloan FA. "Valuing Health Care". Cambridge University Press. (1995).

14. Gujiguemde TR., et al. "A precise method for estimating the economic costs of malaria : Application of the mehtod in a rural area in Burkina Faso (West Africa)". Tropical Medicine and International Health 2 :646-653.

15. Hyder AA., et al. "Measuring the Burden of Disease, Healthy Life Years". American Journal of Public Health 88 (1998): 196202. 
16. Jack W. "Principles of Health Economics for Developing Countries, World Bank Institute". (1999).

17. Kamolratanakul P., et al. "Economic impact of tuberculosis at the household level". International Journal of Tuberculosis and Lung Disease 3 (1999): 596-602.

18. Kind P., et al. "The valuation of quality of life: some psychometric evidence". In The Value of Life and Safety (Edited by Jones-Lee M.W.), North-Holland, Amsterdam (1983) :160.

19. Konradsen F., et al. "Measuring the economic cost of malaria to households in Sri Lanka". American Journal of Tropical Medicine And Hygiene 56 (1997): 656-660.

20. Lonnroth KL M., et al. "Can I afford Free treatment? Perceived consequences of health care provider choices among people with tuberculosis uin Ho Chi Minh City, Vietnam". Social Science and Medicine 52 (2001): 935-948.

21. Drummond MF. et al. "Methods for the Economic Evaluation of Health Care Programmes, Oxford University Press (1997).

22. Malaney P. "Micro-Economic Approaches to Evaluating the Burden of Malaria. Cambridge, MA: Center for International Development, Harvard University, CID Working (2003).

23. McGuire A., et al. "The Economics of Health Care: an introductory text'. London, Routledge and Kegan Paul. (1988).

24. Mc Intyre D and Thiede M. "A Review of Studies Dealing with Economic and Social Consequences of High Medical Expenditure with a Special Focus on the Medical Poverty Trap". Cape Town, South Africa: Health Economics Unit, University of Cape Town (2003).

25. Murray CJL and Lopez AD. "Global Burden of Disease". World Health Organization, Geneva (1996).

26. Needham DM., et al. "Barriers to tuberculosis control in urban Zambia: the economic impact and burden on patients prior to diagnosis". International Journal of Tuberculosis and Lung Disease 2 (1998): 811-817.

27. Onwujekwe 0., et al "Economic burden of malaria illness on households versus that of all other illness episodes: a study in five malaria holo-endemic Nigerian communities". Health Policy 54 (2000): 143-159.

28. Jacobs P. "The Economics of Health and Medical Care". Aspen Publishers, Inc. Gaithersburg, Maryland (1991).

29. Pryer J. "When breadwinners fall ill: preliminary findings from a case study in Bangladesh". IDS Bull 20 (1989): 49-57.

30. Fajeswari R., et al. "Socio- economic impact of tuberculosis on patients and family in India". International Journal of Tuberculosis and Lung Disease 3 (1999): 869-877.

31. Ranson K. "Reduction of catastrophic health care expenditures by a community-based health insurance scheme in
Gujurat, India: current experiences and challenges". Bulletin World Health Organ 80 (2002): 613-621.

32. Rugalema G. "It is not only the loss of labour: HIV/AIDS, loss of household assests and household livelihoods in Bukoba District, Tanzania". Paper presented at the East and Southern Africa Regional Conference on responding to HIV/AIDS. Harare (1998).

33. Russell S. "Ability to pay for health care: concepts and evidence". Health Insurance Plans \& Policy 11 (1996): 219-237.

34. Russell St. "The Economic Burden of Illness for Households in Developing Countries; A Review of Studies Focusing on Malaria, Tuberculosis, and Human Immunodeficiency Virus/ Acquired Immunodeficiency Syndrome". American Journal of Tropical Medicine and Hygiene 71 (2004):147-155.

35. Folland S., et al. "The Economics of health and health care". Macmillan 3rd ed. (2000).

36. Sauerborn R., et al. "Household strategies to cope with the economic costs of illness". Social Science and Medicine 43 (1996): 291-301.

37. Samuel D., et al. "Cost-Effectiveness in Low- and Middle-Income Countries: A Review of the Debates Surrounding Decision Rules". Pharmacoeconomics 27.11 (2009): 903-917.

38. Salomon JA., et al. "Disability weights for the Global Burden of Disease 2013 study" 3 (2015).

39. Shepard DS., et al. "The economic cost of malaria in Africa". Tropical medicine and parasitology 42 (1991): 199-203.

40. Wammes Joost JG, et al. "Cost-effectiveness of methadone maintenance therapy as HIV prevention in an Indonesian high-prevalence setting: a mathematical modeling study." International Journal of Drug Policy 23.5 (2012): 358-364.

41. WHO. Improving Health outcomes of the Poor: The Report of Working Group 5 of the Commission on Macroeconomics and Health Geneva: World Health Organization (2002).

42. Wijewardene K and Spohr M. "An attempt to measure burden of disease using disability adjusted life years for Sri Lanka". ceylon medical journal 45 (2000): 110-115.

43. World Bank, World Development Report: Attacking Poverty. Washington, DC: World Bank. (2000).

\section{Volume 3 Issue 10 October 2019} (c) All rights are reserved by Sushil Ranjan Howlader. 